\title{
Simvastatin/fenofibrate combination in the treatment of dyslipidemia: current evidence
}

This article was published in the following Dove Press journal:

Research and Reports in Endocrine Disorders

18 December 2014

Number of times this article has been viewed

\section{Jose G Jimenez-Montero' Gregory Haft ${ }^{2}$}

'Post Graduate Studies, University of Medical Sciences, San José, Costa Rica; ${ }^{2} \mathrm{Mel}$ and Enid Zuckerman College of Public Health, University of Arizona, Tucson, AZ, USA
Correspondence: Jose G Jimenez-Montero Post Graduate Studies, Universidad de Ciencias Médicas, Department of Endocrinology, Hospital CIMA, PO Box 638-1007, Centro Colon, San José,

Costa Rica

Phone +506 $2208|30|$

Gregory Haft

Mel and Enid Zuckerman College of Public Health, University of Arizona I250 E Grant Road, Tower 2, Tucson, AZ, 85719, USA

Phone +I 5162368533
Background: It has been demonstrated that statins can reduce major cardiovascular complications throughout a broad range of patients with dyslipidemia and multiple cardiovascular risk. Despite the impact of statin therapy on cardiovascular morbidity and mortality, a residual cardiovascular risk remains following lowering of low-density lipoprotein cholesterol. In many patients, optimization of the lipid profile cannot be achieved with statin therapy. Therefore, pharmacologic interventions with non-statin therapy can be used.

Aims: The objective of this review was to analyze current clinical evidence of the effects of simvastatin/fenofibrate combination therapy.

Methods: We searched and analyzed the evidence up to June 2014, regarding the effects of statin/fibrate combination therapy for reducing cardiovascular complications.

Results: Forty-nine studies reporting the efficacy and safety of statin/fibrate combination therapy were analyzed. Of the forty-nine, 19 analyzed the simvastatin/fenofibrate combination therapy. This therapy was demonstrated to be safe and superior to the statin monotherapy in modifying atherogenic dyslipidemia, including lipoprotein subclasses. Nevertheless, in randomized clinical trials cardiovascular endpoints were not significantly different when fenofibrate was added to a standard low-density lipoprotein cholesterol reducing therapy. Of note, in the subgroup analysis, positive results were observed in patients with high triglycerides and low high-density lipoproteins. The inclusion of heterogeneous populations in these studies may explain the mixed results of cardiovascular outcomes seen in randomized clinical trials.

Conclusion: Future clinical studies that rigorously address the effects of simvastatin/ fenofibrate in patients with triglycerides $>2.25 \mathrm{mmol} / \mathrm{L}$ and high density lipoprotein cholesterol $<0.90 \mathrm{mmol} / \mathrm{L}$, will provide a more accurate conclusion regarding the use of simvastatin/ fenofibrate combination therapy. For now, emphasis must be put on non-pharmacological interventions that effectively induce weight loss and strict glycemic control in diabetics. The initiation of simvastatin/fenofibrate combination therapy among patients with residual cardiovascular risk should be employed at the physician's discretion, as this strategy lacks hard cardiovascular end points.

Keywords: dyslipidemia, atherosclerotic cardiovascular disease, residual risk, simvastatin fenofibrate combination therapy

\section{Introduction}

Atherosclerotic cardiovascular disease (ASCVD) is the leading cause of death in adults around the world. In developing countries this condition accounts for $80 \%$ of the global cardiovascular disease burden. ${ }^{1,2}$ In epidemiological studies, a direct relation of elevated low-density lipoprotein cholesterol (LDL-C) with increased risk for the development of ASCVD was demonstrated; whereas high-density lipoprotein cholesterol (HDL-C) 
level was negatively associated..$^{3-6}$ The relationship between triglycerides and cardiovascular disease has elicited considerable debate over the years. Various investigators have shown that hypertriglyceridemia is a univariate predictor of cardiovascular disease but not independent in multivariate analysis. ${ }^{7-15}$ Postprandial hypertriglyceridemia seems to be a better predictor of ASCVD compared to fasting triglyceride levels. ${ }^{16,17}$ The mechanisms associated with increased cardiovascular risk are complex and involve lipid and non-lipid mechanisms. ${ }^{16-18}$

Obesity is increasing worldwide. ${ }^{19}$ This leads to an increased prevalence of hypertriglyceridemia, metabolic syndrome (MetS), ${ }^{20,21}$ and type 2 diabetes. ${ }^{22}$ Of relevance, in South and Central America, the number of people with diabetes will increase by $60 \%$ by $2035 .{ }^{23}$ In patients with familial forms of dyslipidemia, ${ }^{24-27} \mathrm{MetS}$, and diabetes (which is associated with a high incidence of ASCVD), over-nutrition and obesity worsens the lipid profile. ${ }^{28}$

A number of randomized clinical trials (RCTs) have shown that by reducing LDL-C with 3-hydroxy3-methylglutarylcoenzyme A (HMG-CoA) inhibitors (statins), cardiovascular events are reduced in primary and secondary prevention trials. ${ }^{29-45}$ However in these reports, considerable risk for cardiovascular events remains, suggesting that other lipid abnormalities such as hypertriglyceridemia, low HDL-C, high non-HDL-C, apolipoprotein B, and small LDL particles may be implicated in cardiovascular outcomes. ${ }^{16,46,47}$

As of now, recent studies fail to demonstrate therapies that increase HDL-C or those that correct other lipid abnormalities aimed to reduce ASCVD. ${ }^{48-51}$

The Third Report of the Expert Panel on Detection, Evaluation and Treatment of High Cholesterol in Adults (Adult Treatment Panel III) of the National Cholesterol Education Program as well as the 2001 updated version, focused on intensive treatments for patients with coronary artery disease and cardiovascular risk equivalents as assessed with the Framingham algorithm. ${ }^{52,53}$ Statements of the American Association of Clinical Endocrinologists, the Canadian Cardiovascular Society, the European Guidelines, and the International Lipid Society are generally in accordance with the National Cholesterol Education Program. ${ }^{54-57}$

The newly published American College of Cardiology/ American Heart Association guidelines ${ }^{58}$ recommend a risk reduction through moderate to intense statin therapy in:

1. patients with ASCVD;

2. patients with diabetes;

3. patients with primary elevations of LDL-C $>4.9 \mathrm{mmol} / \mathrm{L}$;
4. patients without clinical ASCVD who are 40 to 75 years of age with LDL-C 1.8 to $4.88 \mathrm{mmol} / \mathrm{L}$ and an estimated 10 year ASCVD risk of $\geq 7.5 \%$ calculated by the Pooled Cohort Equations.

These guidelines presented substantial changes and provoked debates. ${ }^{59,60}$ For example, treatment goals for LDL-C and non-HDL-C are no longer recommended. The lack of guidelines provided for treating high triglyceride levels and dyslipidemia after intensive statin therapy, has led to the misunderstanding of which non-statin agents can be recommended. ${ }^{58}$ Considering that an ample spectrum of clinical situations must be taken into account to reduce cardiovascular risk, primary care physicians may face difficulties in deciding on the optimal lipid treatment for patients with persistent dyslipidemia, following optimal statin therapy. ${ }^{16,6-47}$

This report focused primarily on the role of triglycerides in cardiovascular disease and reviewed cardiovascular benefits of treatment with statin/fibrate combination in patients with diabetes and mixed dyslipidemia with residual cardiovascular risk.

\section{Methods}

For the present review we searched PubMed from 1990 to June 2014 using the key words: randomized cardiovascular clinical trials, safety and efficacy of fibrate, statins and fibrate/ statin combination on lipid and lipoprotein profile, adverse effects, morbidity and mortality outcomes.

\section{Results}

We reviewed and fully assessed reports and clinical trials regarding the benefits of lipid lowering therapies on cardiovascular disease. We found forty-nine studies that reported the effects of statins and fibrates combination therapy. Of the forty-nine reports, 19 assessed simvastatin/fenofibrate combination therapy and were the source of discussion (results presented in the Tables).

\section{Dyslipidemia and ASCVD}

Fasting triglycerides are mainly carried in very low-density lipoprotein (VLDL) and their remnants, while in the postprandial state; triglycerides are transported in chylomicrons and their remnants. ${ }^{56}$ As defined by the European Society of Atherosclerosis, triglyceride rich lipoprotein remnants, relate to chylomicron and VLDL particles, which have undergone dynamic remodeling in the plasma after secretion from the intestine or liver. ${ }^{56}$

Under normal conditions these VLDL particles are rapidly cleared from the plasma as they can either be taken via 
liver receptors or transformed into LDL-C. ${ }^{61-63}$ Dyslipidemic patients, with insulin resistance and MetS, who are at high cardiovascular risk, have reduced chylomicron remnants clearance, increased formation and reduced degradation of VLDL triglycerides resulting in the accumulation of triglyceride rich remnants. ${ }^{56,64}$ The mechanisms associated with these lipid alterations are linked to excess apolipoprotein CIII, hepatic lipase, and to postprandial lipemia. ${ }^{63-68}$

It has being demonstrated that LDL-C has a predominant role in atherosclerosis as cholesterol accumulation in the arterial wall is derived primarily from this lipoprotein fraction. ${ }^{69-74}$ LDL-C through the interaction with the arterial wall enters the sub endothelial space where it undergoes modifications. It seems that small dense LDL-C enters at a higher rate than buoyant LDL. ${ }^{75-77}$ Modifications of LDL in the sub endothelial space activates macrophages, thus promoting the lipid laden macrophage formation and initiating the atherosclerotic process. ${ }^{69-73}$

As stated above, LDL-C is considered the main atherogenic lipoprotein particle, but other apolipoprotein B-containing lipoproteins such as triglyceride rich remnants and lipoprotein(a) also contribute to sub endothelial cholesterol accumulation. Triglyceride rich remnants accumulate in plasma, penetrate the arterial intima, and are retained by connective tissue matrix. ${ }^{78-92}$ These particles can be taken up by arterial macrophages leading to foam cell formation, participating in atherogenesis as seen in atherosclerotic lesions. Moreover, triglyceride rich particles have been associated with the progression of coronary artery disease and increased cardiovascular risk. ${ }^{84,85}$ Another line of evidence came from studies which demonstrated that triglyceride rich remnants are associated with impaired vasodilation, enhanced inflammatory responses, cytokine formation, and linked to a pro-thrombotic state. ${ }^{93-95}$

High triglyceride levels are inversely related to low HDL-C, which becomes smaller and triglyceride enriched; these changes have been associated with defective function of HDL. ${ }^{96-98}$ Thus, HDL may lose its putative protective role against atherosclerosis, as normal HDL particles maintain normal endothelial vasoreactivity, reduce oxidative stress and the expression of adhesion molecules and cytokines, among other anti-atherogenic mechanisms. ${ }^{96-98}$

Supporting the notion of the role of triglycerides on cardiovascular disease, a recent study demonstrated that mutations in the coding sequence of particular genes have the ability to alter plasma triglyceride levels. ${ }^{99}$ Specifically, carriers of the apolipoprotein C 3 (APOC3) mutation had plasma triglyceride concentrations of up to $40 \%$ lower than those without it.
Correspondingly, carriers of these mutations were found to have a reduced risk of coronary heart disease. ${ }^{99}$

Thus, the role of triglycerides in atherogenesis may be related to direct and indirect mechanisms. ${ }^{56}$ Some are linked to lipoprotein metabolism, including postprandial hypertriglycemia associated with elevation of triglyceride rich remnants in plasma and promoting cholesterol accumulation in the arterial wall and; generating dysfunctional HDL, that adversely affects cholesterol efflux from macrophages. ${ }^{78-92}$ Indirectly, hypertriglyceridemia, leads to endothelial dysfunction creating favorable conditions for atherogenesis. ${ }^{93-95}$

\section{Clinical management of hypertriglyceridemia and mixed dyslipidemia}

In order to manage hypertriglyceridemia and mixed dyslipidemia, correction of secondary causes of dyslipidemia, and lifestyle changes must be implemented. ${ }^{54-58}$ Adherence to lifestyle modifications and strict glycemic control in diabetics is mandatory. In general, it is recommended that patients should focus on the reduction of saturated fats, trans fats, cholesterol, alcohol, and sugar (sucrose and fructose). ${ }^{100}$ A reduced calorie diet consisting of at least five servings of fruit and vegetables has been known to be beneficial. Furthermore, consuming about $2 \mathrm{~g}$ /day of plant sterols as well as 10-25 g/day of soluble fiber can aid in lowering LDL-C. ${ }^{54-58}$ If the patient is a smoker, every effort should be made to help the patient quit. Physical activity improves lipid profile, increases strength and flexibility, and reduces insulin resistance. Aerobic exercise programs should include at least 30 minutes of moderate to intense activity four to six times a week. Some examples of aerobic exercise could include walking, riding a stationary bicycle, water aerobics, and sporting activities. Additionally, muscle-strengthening activity is recommended at least 2 days a week. ${ }^{101}$

If non-pharmacologic treatment fails to optimize lipid abnormalities, targeting abnormal lipid levels with statins alone or in combination with non-statin drugs can be employed. ${ }^{54-58}$

\section{Fibrates}

Fibrates are agonists of the peroxisome proliferator-activated receptors and lower serum triglycerides by $35 \%-50 \%$. They also increase serum HDL-C by 5\%-20\%. Fibrates diminish hepatic secretion of VLDL while inducing clearance of both chylomicrons and VLDL particles through the activation of LPL and downregulation of apolipoprotein C-III gene expression. ${ }^{102-107}$ 
The lipid lowering effects of gemfibrozil and fenofibrate are comparable. ${ }^{104,105}$ Additionally, some studies state that fibrates reduce lipoprotein(a), ${ }^{106}$ but this concept is controversial. Fenofibrate reduces fibrinogen levels, whereas gemfibrozil has no effect on this parameter. ${ }^{103}$

Fibrates have been associated with increased creatinine and homocysteine levels. ${ }^{107}$ However, this effect is reversible once the discontinuation of the medication has taken place. ${ }^{51,103-105}$

\section{HMG CoA reductase inhibitors}

Statins are competitive inhibitors of HMG CoA reductase, the rate-limiting enzyme required for cholesterol biosynthesis. This reduces the intracellular cholesterol pool and upregulates the LDL receptor. Consequently, this increases the LDL-C uptake and degradation particularly in the liver and reduces plasma LDL-C levels. ${ }^{108}$ Moreover, statins affect VLDL synthesis and moderately reduce plasma triglyceride levels, as well as increase plasma HDL-C. ${ }^{109-111}$

Adverse effects have been reported, such as myopathy, liver dysfunction, and rarely rabdomyolisis. ${ }^{12}$ Recently, an increased risk of developing diabetes has been observed. ${ }^{113-117}$ This increased risk is higher with intensive rather than moderate statin therapy. ${ }^{117}$ However, the beneficial effects of statins on cardiovascular events and mortality outweigh the possibilities of an increased risk of developing diabetes. ${ }^{116}$

\section{Evidence of fibrates for the prevention of cardiovascular complications}

Clinical intervention studies, in which diabetic and nondiabetic patients received fibrates, showed a reduction in cardiovascular events in primary and secondary prevention trials. The Helsinki Heart Study showed benefits from gemfibrozil therapy in patients with high triglyceride levels $(>2.25 \mathrm{mmol} / \mathrm{L})$ and LDL-C/HDL-C ratio $>5.0 .{ }^{118}$ The Veterans Affairs High-Density Lipoprotein Cholesterol Intervention Trial Study (VA-HIT) evaluated the effect of gemfibrozil therapy in patients with a history of cardiovascular disease, low HDL-C, relatively low LDL-C, and triglyceride levels $\leq 3.38 \mathrm{mmol} / \mathrm{L} .{ }^{119}$ Fibrate therapy in patients with type 2 diabetes reduced the rate of coronary heart disease events. ${ }^{120}$ The Bezafibrate Infarction Prevention (BIP) study showed a favorable effect on lipid parameters but no reduction in coronary events. ${ }^{121}$ In The Diabetes Atherosclerosis Intervention Study, fenofibrate showed a reduction in LDL particle size and a decreased progression of coronary heart disease, but no differences in cardiovascular outcomes for type
2 diabetics. ${ }^{122}$ The Field study was performed among more than 9,000 type 2 diabetics and used micronized fenofibrate. While there was no significant change in the rates of coronary outcomes, there was however, a slight increase in mortality rates. ${ }^{123,124} \mathrm{~A}$ meta-analysis of RCTs comparing fibrate with placebo illustrated a reduction of major cardiovascular and coronary events by $10 \%$ and $13 \%$, respectively. Additionally, a significant reduction in revascularizations was demonstrated, but no effect on all-cause mortality was noted. ${ }^{124}$

\section{Evidence of statins for the prevention of cardiovascular complications}

Angiographic studies with statins have shown slow progression and induced regression of coronary lesions. ${ }^{31}$ RCTs were performed among patients with low, moderate, and high LDL-C, as well as among patients with the presence and absence of cardiovascular disease and diabetes. ${ }^{29-44,125}$

In patients at low risk of vascular events, a meta-analysis showed that a $1 \mathrm{mmol} / \mathrm{L}$ reduction in LDL-C resulted in the absolute reduction of major vascular events of approximately eleven per 1,000 over 5 years. ${ }^{42,43}$ In 2010, data from a metaanalysis of 170,000 participants in 26 RCTs demonstrated that by reducing LDL-C by $2-3 \mathrm{mmol} / \mathrm{L}$, a $40 \%-50 \%$ reduction in cardiovascular risk would be obtained. ${ }^{42}$

Based on this evidence, the American College of Cardiology/American Heart Association guidelines recommended intensive statin doses for cardiovascular risk reduction. ${ }^{58}$ However, not all the patients tolerate this regimen and alternative therapeutic approaches are needed. ${ }^{52-57}$ Recent studies in hypercholesterolemic and diabetic patients have shown that the combination of ezetimibe/simvastatin was more effective than atorvastatin or rosuvastatin monotherapy in lowering LDL-C compared to statin therapy. ${ }^{126}$ Furthermore, a recent report showed that in diabetic patients who received the ezetimibe/atorvastatin therapy, a greater regression of plaque volume was present in comparison to atorvastatin alone. ${ }^{127}$ Ongoing studies will determine if this combination therapy will reduce cardiovascular mortality.

\section{Evidence of statin/fibrate combination for the prevention of cardiovascular complications}

In many patients at risk of ASCVD, a residual cardiovascular risk remains after statin therapy has been implemented and LDL-C targets achieved. ${ }^{16,45-47}$ Such patients typically display high triglycerides and low HDL-C 
levels. Thus, as reported recently, ${ }^{128-130}$ managing residual cardiovascular risk needs to be addressed in patients on optimal statin therapy. Statin/fibrate combination therapy could be considered as a logical approach to optimize lipid and lipoprotein levels in such patients.

Because gemfibrozil has been shown to inhibit statin acid glucuronidation and increases the area under the curve when both drugs are consumed, this agent is generally not recommended to be used with statins. ${ }^{131}$ In contrast, co-administration of statins and fenofibrate does not affect the pharmacokinetics of statins. Thus, statin/fenofibrate combination therapy is an attractive alternative for patients with mixed dyslipidemia and for those in whom lipid abnormalities persisted after initial statin therapy. ${ }^{131-133}$

Numerous studies specifically evaluated the effects of simvastatin/fenofibrate combination therapy. ${ }^{132-165}$ Additional reductions in lipid and lipoprotein concentrations were observed in statin/ fenofibrate combination therapy, in comparison to statin monotherapy. ${ }^{149-163}$ Also, the combination therapy reduced inflammatory markers including fibrinogen, high-sensitivity $\mathrm{C}$ reactive protein, and plasminogen activator inhibitor-1 levels; ${ }^{156,158}$ and improved postprandial endothelial dysfunction. ${ }^{145}$

As seen in Table 1, eight randomized double-blind efficacy studies using simvastatin/fenofibrate combination therapy were compared to statins alone. ${ }^{144,153,155-160}$ These studies were performed in diabetics and non-diabetics with mixed dyslipidemia, as well as patients with and without cardiovascular disease.

The effect of simvastatin/fenofibrate combination therapy was not restricted to reductions in total-cholesterol, triglycerides, and increments of HDL-C. In patients with mixed dyslipidemia, the addition of statin/fenofibrate statins caused a further reduction of VLDL plus intermediate density lipoprotein and VLDL plus intermediate density lipoprotein apolipoprotein B of $36 \%$ and $34 \%$, respectively and changes in the pattern of LDL particles. ${ }^{152,154}$ Likewise, other investigators, ${ }^{157}$ showed a shift from LDL pattern B to the more buoyant LDL pattern. This was specifically noted in diabetic patients with mixed dyslipidemia who were treated with simvastatin $20 \mathrm{mg}$ plus fenofibrate $160 \mathrm{mg} .{ }^{160}$

\section{Outcome of clinical trials}

Due to the positive effects of statin/fibrate combination, additional studies were developed in patients with diabetes and high cardiovascular risk to assess the benefits on cardiovascular outcomes.

Of the studies, three RCTs presented cardiovascular outcomes. ${ }^{51,163,164}$ As seen in Table 2, the effectiveness of the combination therapy in patients with ischemic heart disease, was measured by echocardiographic and exercise tests. Improved myocardial function, as well as a significant improvement in left ventricular ejection fraction, resulted in favorable changes in exercise performance. ${ }^{163}$ Similarly, in the FIRST study, ${ }^{164}$ the simvastatin/fenofibrate combination therapy induced changes in carotid intima media thickness (cIMT) - a surrogate marker of cardiovascular disease - in subgroups of patients including those $\geq 60$ years, with a history of coronary artery disease, cIMT $>0.795 \mathrm{~mm}$, with baseline triglycerides in the middle tertile, and statin use at entry to study. Nonetheless, both of these studies were relatively small, of short duration, and no effect on mortality was demonstrated.

In The Action to Control Cardiovascular Risk in Diabetes (ACCORD lipid trial),${ }^{51}$ the only cardiovascular outcome study, the addition of fenofibrate (160 or $54 \mathrm{mg}$ /day) to simvastatin therapy (20-40 mg/day) did not demonstrate total population mortality effects. In this study, the dyslipidemic patients had an elevated relative cardiovascular risk compared to those without dyslipidemia despite the fact that median LDL-C achieved optimal levels. In the whole group the primary outcome occurred at a rate of $2.4 \% /$ year for placebo and $2.2 \% /$ year for combination therapy, results that were not significantly different $(P=0.32) .{ }^{51}$ In the prespecified subgroup analysis, men showed a lower primary event with the combination therapy and the dyslipidemic patients had $31 \%$ lower outcomes compared to the rest of the participants ( $P$-value not reported), suggesting that in such patients the combination therapy could offer additional benefits in reducing ASCVD risk. ${ }^{51}$ Interestingly, when the postprandial triglyceride and intestinal lipoprotein remnants excursion was examined in dyslipidemic patients from the ACCORD lipid trial, ${ }^{166}$ the statin/fenofibrate combination therapy significantly reduced apolipoprotein B 48 remnants' lipoprotein particles. Since these particles have atherogenic potential, the effects of such therapy could benefit diabetic dyslipidemic patients. ${ }^{166}$

Side effects of statin/fibrate combination therapy include muscle and liver toxicity as well as renal complications. ${ }^{133,152,160}$ In comparison to gemfibrozil, fenofibrate is less associated with rhabdomyolysis when used in combination with statins. ${ }^{138}$ Additionally, the combination therapy has the tendency to increase creatinine concentrations, however, this adverse effect is reversible with the discontinuation of the medication. ${ }^{51,138,139}$

Likewise, when renal impairment is present, lower doses of fenofibrate is recommended. ${ }^{51,138,139}$ Additionally, simvastatin/ 


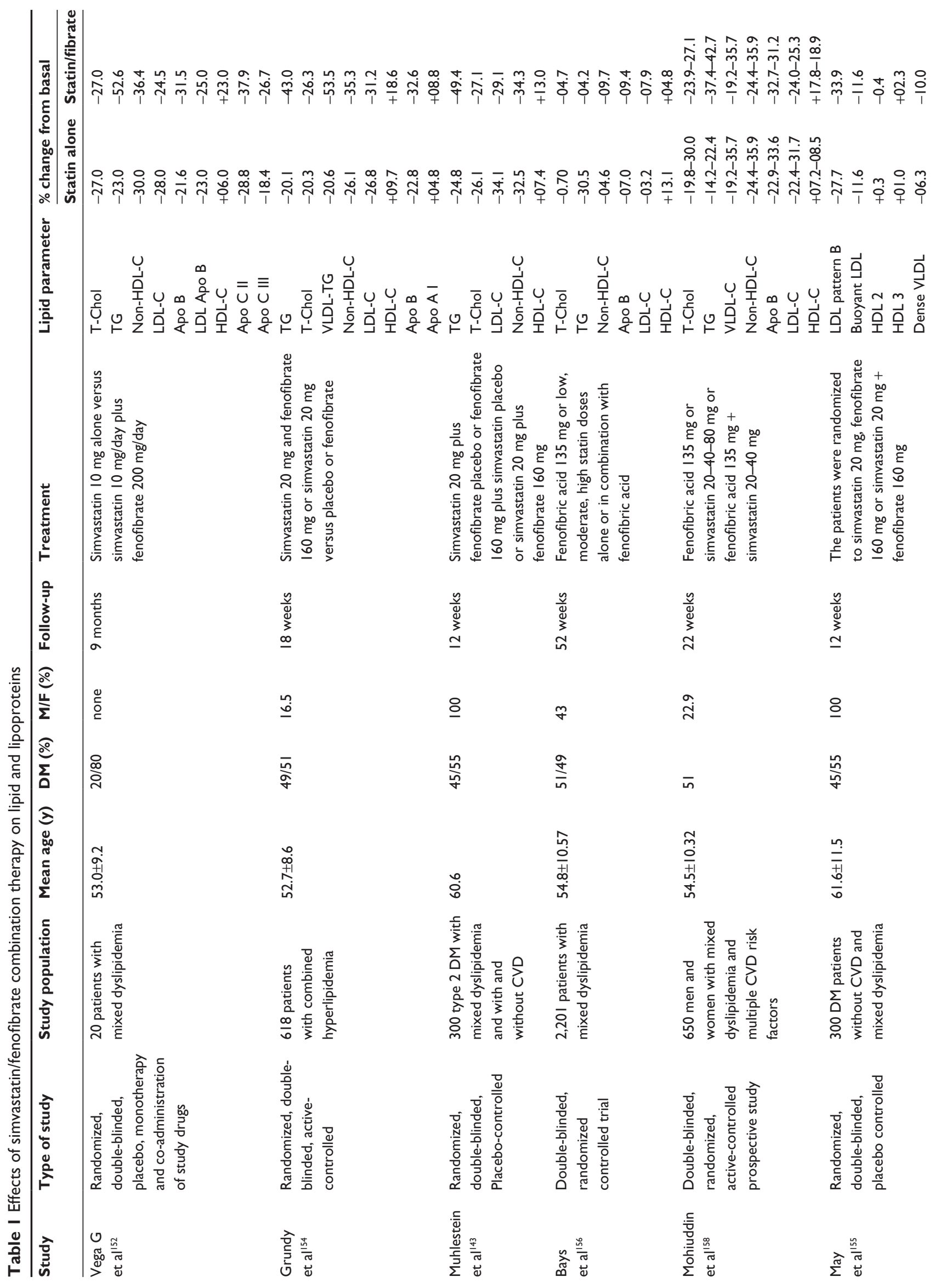




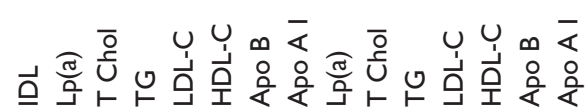

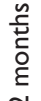

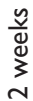

으

$\hat{\mathrm{N}}$

通

$\frac{\infty}{\stackrel{N}{ก}}$

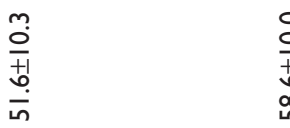

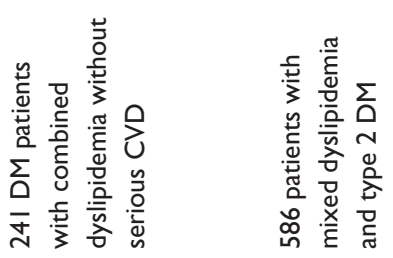

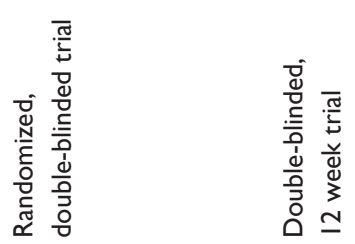

竞

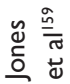

fenofibrate combination therapy should be avoided in patients receiving macrolides, antifungals, cyclosporine, and protease inhibitors, as these agents are cytocromes $3 \mathrm{~A} 4$ inhibitors and can affect statin metabolism. ${ }^{138,139}$

\section{Discussion}

Dyslipidemia characterized by elevated triglycerides, low HDL-C and moderate elevations of LDL-C, is common throughout diverse populations and is often associated with obesity, MetS, and type 2 diabetes. ${ }^{45-47}$ The characteristic lipid abnormality present in these patients largely contributes to the increased rate of cardiovascular complications. As indicated above, the association of triglycerides and ASCVD is complex. Conflicting results regarding fasting triglyceride concentrations and ASCVD exists, as this relationship is not sustained after adjusting for other lipid variables. However, it has been recognized that postprandial lipemia (which is associated with the presence of triglyceride rich remnant particles, small LDL-C, and a decrease in HDL-C) correlates with cIMT and predicts the risk of cardiovascular disease more accurately than fasting triglyceride concentrations. The mechanisms that link triglycerides with ASCVD are related to the accumulation of triglyceride rich lipoproteins including chylomicron and VLDL remnants, modifications in HDL composition, ${ }^{96,97}$ and to other non-lipidic alterations which lead to endothelial dysfunction and pro-thrombotic effects. ${ }^{16,93-95}$ Postprandial lipemia has been observed in various clinical situations. Some examples include individuals with MetS, diabetes mellitus, with increased visceral adipose tissue, postmenopausal states, and patients with coronary artery disease. ${ }^{87-90}$

As demonstrated in the large interventional studies that target LDL-C with statins, a decrease in cardiovascular risk has been noted throughout a wide range of patients, including diabetics with borderline LDL-C concentrations..$^{40-43}$ In the ACCORD lipid trial, hard cardiovascular end points with the statin/fibrate combination therapy, in the total population study were unfavorable. However, those individuals with fasting and postprandial hypertriglyceridemia seemed to have benefited from the simvastatin/fenofibrate combination therapy. ${ }^{166}$ Although not confirmed, differences in the lipid characteristics throughout the participants may explain the negative outcomes. The patients who could benefit the most from this therapeutic strategy (high triglycerides/low HDL, postprandial lipemia, and small dense LDL) were not significantly represented. Of note, in the ACCORD lipid study only $15 \%$ of the overall cohort had dyslipidemia. ${ }^{51}$ Similarly, in the FIRST study, changes in cIMT-favored subgroups of 


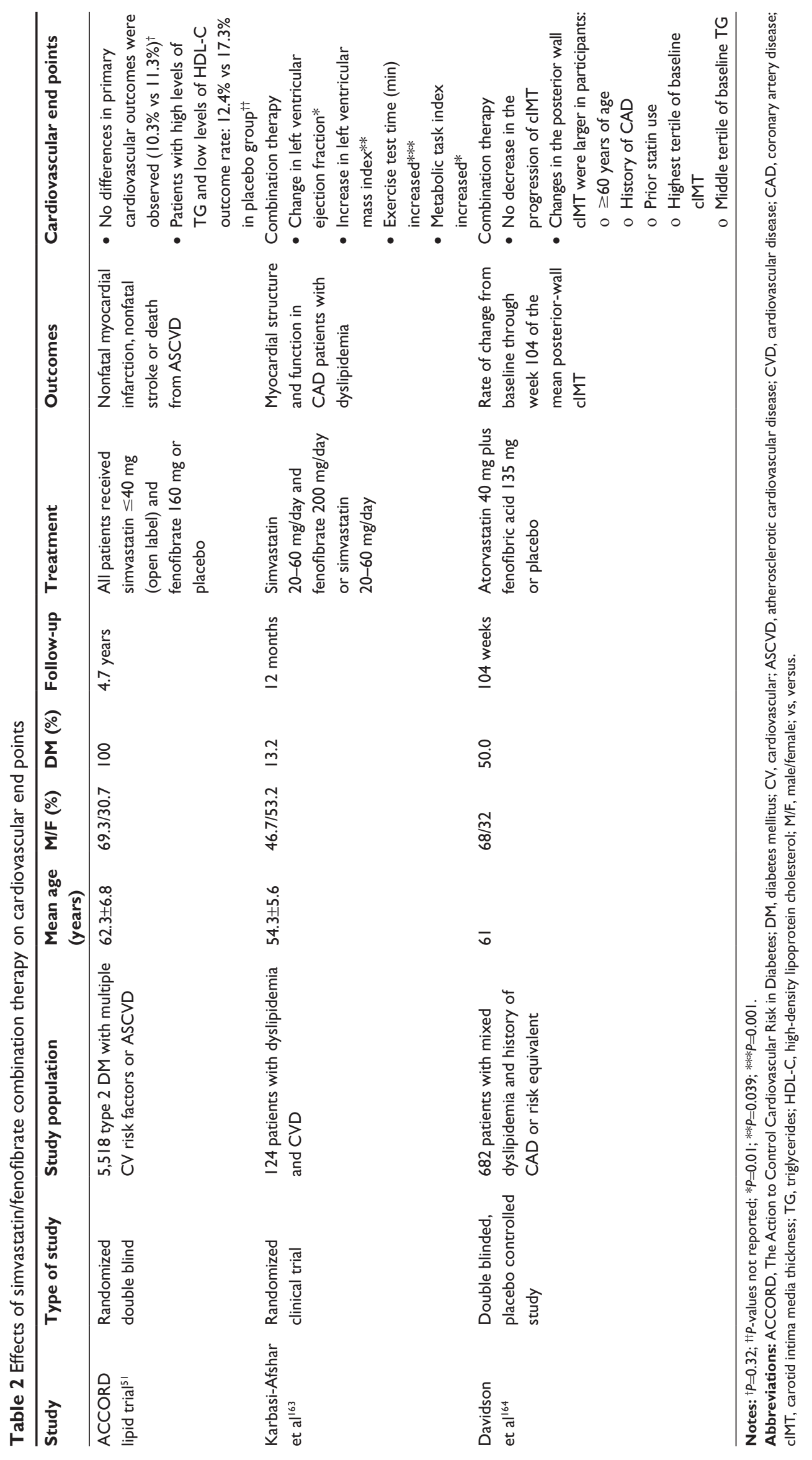


patients including those with baseline triglycerides in the middle tertile. ${ }^{164}$

In conclusion, statin-fenofibrate therapy should theoretically benefit the subgroup of patients with high triglycerides/ low HDL. Although there is not enough evidence to prove this correct. It is reassuring that a new intervention study: Simvastatin and Fenofibrate vs Simvastatin Alone in Patients with Type 2 Diabetes Mellitus and Acute Coronary Syndrome is ongoing. ${ }^{167}$ This study hypothesizes that early administration of combined simvastatin/fenofibrate therapy in an extremely high-risk population of patients with type 2 diabetes mellitus and hypertriglyceridemia with acute coronary syndrome will be effective. However, to accurately address the effects on cardiovascular mortality of the combination therapy, a more specific clinical trial is necessary. This can be achieved by recruiting the specific patient population whose benefits were mentioned in previous studies. ${ }^{16,51,164}$ Until this investigation is complete, weight loss must be encouraged in dyslipidemic patients and in diabetics strict glycemic control should be mandatory. Thus for now, the use of simvastatin/fenofibrate combination therapy should only be used at physician's discretion.

\section{Acknowledgments}

We would like to thank Dr A Gonzalez-Monge, Dr Yulino Castillo, Dr Carolyn Newman, and Lic Kathya ArrietaMorera for their assistance in the literature search.

\section{Disclosure}

Dr JG Jimenez-Montero has been on the Insulin Advisory Board and received a research grant from Sanofi-Aventis. Dr G Haft reports no conflict of interest in this work.

\section{References}

1. Reddy KS, Yusuf S. Emerging epidemic of cardiovascular disease in developing countries. Circulation. 1998;97(6):596-601.

2. [No authors listed]. WHO publishes definitive atlas on global heart disease and stroke epidemic. Indian J Med Sci. 2004;58(9):405-406.

3. Kannel WB, Castelli WP, Gordon T, McNamara PM. Serum cholesterol, lipoproteins, and the risk of coronary heart disease. The Framingham Study. Ann Intern Med. 1971;74(1):1-12.

4. Miller GJ, Miller NE. Plasma-high-density-lipoprotein concentration and development of ischaemic heart-disease. Lancet. 1975;1(7897):16-19.

5. Stamler J, Wentworth D, Neaton JD. Is relationship between serum cholesterol and risk of premature death from coronary heart disease continuous and graded? Findings in 356,222 primary screenees of the Multiple Risk Factor Intervention Trial (MRFIT). JAMA. 1986;256(20): 2823-2828.

6. Yusuf S, Hawken S, Ounpuu S, et al. Effect of potentially modifiable risk factors associated with myocardial infarction in 52 countries (the INTERHEART study): case-control study. Lancet. 2004;364(9438):937-952.

7. Goldstein JL, Hazzard WR, Schrott HG, Bierman EL, Motulsky AG. Hyperlipidemia in coronary heart disease. I. Lipid levels in 500 survivors of myocardial infarction. J Clin Invest. 1973;52(7):1533-1543.
8. Hulley SB, Rosenman RH, Bawol RD, Brand RJ. Epidemiology as a guide to clinical decisions. The association between triglyceride and coronary heart disease. N Engl J Med. 1980;302(25):1383-1389.

9. Criqui MH, Heiss G, Cohn R, et al. Plasma triglyceride level and mortality from coronary heart disease. $N$ Engl J Med. 1993;328(17): $1220-1225$.

10. Assmann G, Schulte H, Von Eckardstein A. Hypertriglyceridemia and elevated lipoprotein(a) are risk factors for major coronary events in middle-aged men. Am J Cardiol. 1996;77(14):1179-1184.

11. Stampfer MJ, Krauss RM, Ma J, et al. A prospective study of triglyceride level, low density lipoprotein particle diameter, and risk of myocardial infarction. JAMA. 1996;276(11):882-888.

12. Hokanson JE, Austin MA. Plasma triglyceride level is a risk factor for cardiovascular disease independent of high-density lipoprotein cholesterol level: a meta-analysis of population-based prospective studies. J Cardiovasc Risk. 1996;3(2):213-219.

13. Sarwar N, Danesh J, Eiriksdottir G, et al. Triglycerides and the risk of coronary heart disease: 10,148 incident cases among 262,525 participants in 29 Western prospective studies. Circulation. 2007;115(4): $450-458$.

14. Miller M, Stome NJ, Ballantyne C, et al. Triglycerides and cardiovascular disease: a scientific statement from the American Heart Association. Circulation. 2011;123(20):2292-2333.

15. Harchaoui KE, Visser ME, Kastelein JJ, Stroes ES, Dallinga-thie GM. Triglycerides and cardiovascular risk. Curr Cardiol Rev. 2009;5(3): 216-222.

16. Chapman MJ, Ginsberg HN, Amarenco P, et al. Triglyceride-rich lipoproteins and high-density lipoprotein cholesterol in patients at high risk of cardiovascular disease: evidence and guidance for management. Eur Heart J. 2011;32(11):1345-1361.

17. Nordestgaard BG, Benn M, Schnohr P, Tybjaerg-Hansen A. Nonfasting triglycerides and risk of myocardial infarction, ischemic heart disease, and death in men and women. JAMA. 2007;298(3):299-308.

18. Bansal S, Buring JE, Rifai N, et al. Fasting compared with nonfasting triglycerides and risk of cardiovascular events in women. JAMA. 2007;298(3):309-316.

19. Ng M, Fleming T, Robisnon M, et al. Global, regional, and national prevalence of overweight and obesity in children and adults during 1980-2013: a systematic analysis for the Global Burden of Disease Study 2013. Lancet. 2014;384(9945):766-781.

20. Ford ES, Li C, Zhao G, Pearson WS, Mokdad AH. Hypertriglyceridemia and its pharmacologic treatment among US adults. Arch Intern Med. 2009;169(6):572-578.

21. Aguilar-Salinas CA, Olaiz G, Valles V, et al. High prevalence of low HDL cholesterol concentrations and mixed hyperlipidemia in a Mexican nationwide survey. J Lipid Res. 2001;42(8):1298-1307.

22. Wong McClure R, Leandra Abarca Gómez, Giselle Rovira Jiménez, et al. Vigilancia de los Factores de Riesgo Cardiovascular 2011. [Cardiovascular risk factor surveillance 2011]. Caja Costarricense de Seguro Social, Costa Rica. Spanish.

23. International Diabetes Federation. IDF Diabetes Atlas, Sixth Edition. Brussels, Belgium: International Diabetes Federation, 2013. Available from: http://www.idf.org/sites/default/files/EN_6E_Atlas_ Full_0.pdf. Accessed October 5, 2014.

24. Genest JJ Jr, Martin-Munley SS, Mcnamara JR, et al. Familial lipoprotein disorders in patients with premature coronary artery disease. Circulation. 1992;85(6):2025-2033.

25. Austin MA, Mcknight B, Edwards KL, et al. Cardiovascular disease mortality in familial forms of hypertriglyceridemia: A 20-year prospective study. Circulation. 2000;101(24):2777-2782.

26. Ginsberg HN. Hypertriglyceridemia: new insights and new approaches to pharmacologic therapy. Am J Cardiol. 2001;87(10):1174-1180.

27. Hopkins PN, Heiss G, Ellison C, et al. Coronary artery disease risk in familial combined hyperlipidemia and familial hypertriglyceridemia. A case-control comparison from the National Heart, Lung, and Blood Institute Family Heart Study. Circulation. 2003;108(5): 519-523. 
28. Carr MC, Brunzell JD. Abdominal obesity and dyslipidemia in the metabolic syndrome: importance of type 2 diabetes and familial combined hyperlipidemia in coronary artery disease risk. J Clin Endocrinol Metab. 2004;89(6):2601-2607.

29. Shepherd J, Cobbe SM, Ford I, et al. Prevention of coronary heart disease with pravastatin in men with hypercholesterolemia. 1995. Atheroscler Suppl. 2004;5(3):91-97.

30. Furberg CD, Adams HP Jr, Applegate WB, et al. Effect of lovastatin on early carotid atherosclerosis and cardiovascular events. Asymptomatic Carotid Artery Progression Study (ACAPS) Research Group. Circulation. 1994;90(4):1679-1687.

31. Takayama T, Hiro T, Yamagishi M, et al. Effect of rosuvastatin on coronary atheroma in stable coronary artery disease. Circ J. 2009;73(11): 2120-2117.

32. Gotto AM, Whitney E, Stein EA, et al. Relation between baseline and on-treatment lipid parameters and first acute major coronary events in the Air Force/Texas Coronary Atherosclerosis Prevention Study (AFCAPS/TexCAPS). Circulation. 2000;101(5):477-484.

33. Sacks FM, Pfeffer MA, Moye LA, et al. The effect of pravastatin on coronary events after myocardial infarction in patients with average cholesterol levels. Cholesterol and Recurrent Events Trial investigators. N Engl J Med. 1996;335(14):1001-1009.

34. [No authors listed]. Prevention of cardiovascular events and death with pravastatin in patients with coronary heart disease and a broad range of initial cholesterol levels. The Long-Term Intervention with Pravastatin in Ischaemic Disease (LIPID) Study Group. N Engl J Med. 1998;339(19):1349-1357.

35. ALLHAT Officers and Coordinators for the ALLHAT Collaborative Research Group. The Antihypertensive and Lipid-Lowering Treatment to Prevent Heart Attack Trial. Major outcomes in moderately hypercholesterolemic, hypertensive patients randomized to pravastatin vs usual care: The Antihypertensive and Lipid-Lowering Treatment to Prevent Heart Attack Trial (ALLHAT-LLT). JAMA. 2002;288(23): 2998-3007.

36. Packard CJ, Ford I, Robertson M, et al. Plasma lipoproteins and apolipoproteins as predictors of cardiovascular risk and treatment benefit in the PROspective Study of Pravastatin in the Elderly at Risk (PROSPER). Circulation. 2005;112(20):3058-3065.

37. Ridker PM, Danielsson E, Fonseca FA, et al. Rosuvastatin to prevent vascular events in men and women with elevated C-reactive protein. N Engl J Med. 2008;359(21):2105-2207.

38. [No authors listed]. Randomised trial of cholesterol lowering in 4444 patients with coronary heart disease: the Scandinavian Simvastatin Survival Study (4S). Lancet. 1994;344(8934):1383-1389.

39. Heart Protection Study Collaborative Group. MRC/BHF Heart Protection Study of Cholesterol lowering with simvastatin in 20536 high-risk individuals: a randomised placebo-controlled trial. Lancet. 2002;360(9326):7-22.

40. Colhoun HM, Betteridge DJ, Durrington PN, et al. Primary prevention of cardiovascular disease with atorvastatin in type 2 diabetes in the Collaborative Atorvastatin Diabetes Study (CARDS): multicentre randomised placebo-controlled trial. Lancet. 2004;364(9435):685-696.

41. Deedwania P, Barter P, Carmena R, et al. Reduction of low-density lipoprotein cholesterol in patients with coronary heart disease and metabolic syndrome: analysis of the Treating to New Targets study. Lancet. 2006;368(9539):919-928.

42. Cholesterol Treatment Trialists' (CTT) Collaboration, Baigent C, Blackwell L, et al. Efficacy and safety of more intensive lowering of LDL cholesterol: a meta-analysis of data from 170,000 participants in 26 randomised trials. Lancet. 2010;376(9753):1670-1681.

43. Taylor F, Huffman MD, Macedo AF, et al. Statins for the primary prevention of cardiovascular disease. Cochrane Database Syst Rev. 2013;1:CD004816.

44. Ballantyne CM, Olsson AG, Cook TJ, Mercuri MF, Pedersen TR, Kjekshus J. Influence of low high-density lipoprotein cholesterol and elevated triglyceride on coronary heart disease events and response to simvastatin therapy in 4S. Circulation. 2001;104(25):3046-3051.
45. Mora S, Wenger NK, Demicco DA, et al. Determinants of residual risk in secondary prevention patients treated with high- versus low-dose statin therapy: the Treating to New Targets (TNT) study. Circulation. 2012;125(16):1979-1987.

46. Fruchart JC, Sacks F, Hermans MP, et al. The Residual Risk Reduction Initiative: a call to action to reduce residual vascular risk in patients with dyslipidemia. Am J Cardiol. 2008;102(Suppl 10):1K-34K.

47. Brunzell JD, Davidson M, Furber CD, et al. Lipoprotein management in patients with cardiometabolic risk. Consensus Conference Report From the American Diabetes Association and the American College of Cardiology Foundation. J Am Coll Cardiol. 2008;51(15): 1512-1524.

48. Barter PJ, Caulfield M, Eriksson M, et al. Effects of torcetrapib in patients at high risk for coronary events. N Engl J Med. 2007;357(21): 2109-2122.

49. AIM-HIGH Investigators, Boden WE, Probstfield JL, et al. Niacin in patients with low HDL cholesterol levels receiving intensive statin therapy. N Engl J Med. 2011;365(24):2255-2267.

50. HPS2-THRIVE Collaborative Group, Landray MJ, Haynes R, et al. Effects of extended-release niacin with laropiprant in high-risk patients. N Engl J Med. 2014;371(3):203-212.

51. ACCORD Study Group, Grinsberg HN, Elam MB, et al. Effects of Combination Lipid Therapy in Type 2 Diabetes Mellitus. NEngl J Med. 2010;362(17):1563-1574.

52. Expert Panel on detection evaluation and treatment of high cholesterol in adults. Executive Summary of The Third Report of The National Cholesterol Education Program (NCEP) Expert Panel on Detection, Evaluation, And Treatment of High Blood Cholesterol In Adults (Adult Treatment Panel III). JAMA. 2001;285(19):2486-2497.

53. Grundy SM, Cleeman J I, Merz CN, et al. Implications of recent clinical trials for the National Cholesterol Education Program Adult Treatment Panel III guidelines. Circulation. 2004;110(2):227-239.

54. Jellinger PS, Smith DA, Mehta AE, et al. American Association of Clinical Endocrinologists' guidelines for management of dyslipidemia and prevention of atherosclerosis. Endocr Pract. 2012;18 Suppl $1: 1-78$.

55. Anderson TJ, Grégorie J, Hegele RA, et al. Society Guidelines 2012 Update of the Canadian Cardiovascular Society Guidelines for the Diagnosis and Treatment of Dyslipidemia for the Prevention of Cardiovascular Disease in the Adult. Can J Cardiol. 2013;29(2): $151-167$.

56. Perk J, De Backer G, Gohlke H, et al. European guidelines on cardiovascular disease prevention in clinical practice (version 2012). The Fifth Joint Task Force of the European Society of Cardiology and Other Societies on Cardiovascular Disease Prevention in Clinical Practice (constituted by representatives of nine societies and by invited experts). Eur Heart J. 2012;33(13):1635-1701.

57. Expert Dyslipidemia Panel of the International Atherosclerosis Society Panel members. An International Atherosclerosis Society Position Paper: Global recommendations for the management of dyslipidemiaFull report. J Clin Lipidol. 2014;8(1):29-60.

58. Stone NJ, Robinson JG, Lichtenstein AH, et al. 2013 ACC/AHA Guideline on the Treatment of Blood Cholesterol to Reduce Atherosclerotic Cardiovascular Risk in Adults: A Report of the American College of Cardiology/American Heart Association Task Force on Practice Guidelines. J Am Coll Cardiol. 2014;63(25 Pt B): 2889-2934.

59. Pencina MJ, Navar-Boggan AM, D’Agostino RB, et al. Application of new cholesterol guidelines to a population based-sample. $N$ Engl J Med. 2014;370(15):1422-1431.

60. Ridker PM, Cook NR. Statins: the new American guidelines for prevention of cardiovascular disease. Lancet. 2014;382(9917):1762-1765.

61. Brown MS, Goldstein JL. A receptor-mediated pathway for cholesterol homeostasis. Science. 1986;232(4746):34-47.

62. Fredrickson DS, Levy RI, Lees RS. Fat transport in lipoproteins - an integrated approach to mechanisms and disorders. $N$ Engl J Med. 1967;276(1-5):34-281. 
63. Ginsberg HN, Le NA, Golberg IJ, et al. Apolipoprotein B metabolism in subjects with deficiency of apolipoprotein CIII and A I. Evidences that apolipoprotein CIII inhibits catabolism of triglyceride-rich lipoproteins by lipoprotein lipase in vivo. J Clin Invest. 1986;78(5): 1287-1290.

64. Chan DC, Watts GF. Dyslipidaemia in the metabolic syndrome and type 2 diabetes: pathogenesis, priorities, pharmacotherapies. Expert Opin Pharmacother. 2011;12(1):13-30.

65. Oram JF, Vaughan AM. ATP-Binding cassette cholesterol transporters and cardiovascular disease. Circ Res. 2006;99(10):1031-1043.

66. Tall AR, Yan-Chavert L, Terasaka N, Pagle T, Wang N. HDL, ABC transporters, and cholesterol efflux: implications for the treatment of atherosclerosis. Cel Metab. 2008;7(5):365-375.

67. Glomset JA. The plasma lecithins:cholesterol acyltransferase reaction. J Lipid Res. 1968;9(2):155-167.

68. Agellon LB, Walsh A, Hayek T, et al. Reduced high density lipoprotein cholesterol in human cholesteryl ester transfer protein transgenic mice. J Biol Chem. 1991;266(17):10796-10801.

69. Ross R, Glomset JA. Atherosclerosis and the arterial smooth muscle cell: proliferation of smooth muscle is a key event in the génesis of lesions of aterosclerosis. Science. 1973;180(4093):1332-1339.

70. Berglund L, Brunzell JD, Goldberg AC, et al. Evaluation and treatment of hypertriglyceridemia: an Endocrine Society clinical practice guideline. J Clin Endocrinol Metab. 2012;97(9):2969-2989.

71. Handsson GK. Inflammation, atherosclerosis and coronary artery disease. $N$ Engl J Med. 2005;352(16):1685-1695.

72. Hurt-Camejo E, Olsson U, Wiklund O, Bondjers G, Camejo G. Cellular consequences of the association of apoB lipoproteins with proteoglycans. Potential contribution to atherogenesis. Ateroscler Thromb Vasc Biol. 1997;17(6):1011-1117.

73. Skålén K, Gustafsson M, Rydberg EK, et al. Subendothelial retention of atherogenic lipoproteins in early atherosclerosis. Nature. 2002;417(6890):750-754.

74. Lamarche B, Tchernof A, Moorjni S, et al. Small, dense low-density lipoprotein particles as a predictior of the risk of ischemic heart disease in men. Prospective results from the Québec Cardiovascular Study. Circulation. 1997;95(1):69-75.

75. Park YM, Febbraio M, Silverstein RL. CD36 modulates migration of mouse and human macrophages in response to oxidize LDL and may contribute to macrophage trapping in the arterial intima. J Clin Invest. 2009;119(1):136-145.

76. Mora S, Szklo M, Otvos JD, et al. LDL particle subclasses, LDL particle size, and carotid atherosclerosis in the Multi-Ethnic Study of Atherosclerosis (MESA). Atherosclerosis. 2007;192(1):211-217.

77. Austin MA, Breslow JL, Hennekens CH, et al. Low-density lipoproteins subclass patterns and risk of myocardial infarction. JAMA. 1998;260(13):1917-1921.

78. Ginsberg HN. New perspectives on atherogenesis: Role of abnormal triglyceride-rich lipoprotein metabolism. Circulation. 2002;106(16): 2137-2142.

79. Rapp JH, Lespine A, Hamilton RL, et al. Triglyceride-rich lipoproteins isolated by selected-affinity anti-apolipoprotein B immunosorption from human atherosclerotic plaque. Arterioscler Thromb. 1994;14(11): 1767-1774.

80. Daugherty A, Lange LG, Sobel BE, Schonfeld G. Aortic accumulation and plasma clearance of b-VLDL and HDL: effects of dietinduced hypercholesterolemia in rabbits. J Lipid Res. 1985;26(8): 955-963.

81. Proctor SD, Mamo JC. Retention of fluorescent-labelled chylomicron remnants within the intima of the arterial wall - evidence that plaque cholesterol may be derived from post-prandial lipoproteins. Eur J Clin Invest. 1998;28(6):497-503.

82. Goldstein JL, Ho YK, Brown MS, Innerarity TL, Mahley RW. Cholesteryl ester accumulation in macrophages resulting from receptor-mediated uptake and degradation of hypercholesterolemic canine beta-very low density lipoproteins. J Biol Chem. 1980;255(5): 1839-1848.
83. Pitas RE, Innerarity TL, Mahley RW. Foam cells in explants of atherosclerotic rabbit aortas have receptors for beta-very low density lipoproteins and modified low density lipoproteins. Arteriosclerosis. 1983;3(1):2-12.

84. Alaupovic P, Mack WJ, Knight-Gibson C, Hodis HN. The role of triglyceride-rich lipoprotein families in the progression of atherosclerotic lesions as determined by sequential coronary angiography from a controlled clinical trial. Arterioscler Thromb Vasc Biol. 1997;17(4): 715-722

85. Grønholdt ML, Nordestgaard BG, Nielsen TG, Sillesen H. Echolucent carotid artery plaques are associated with elevated levels of fasting and postprandial triglyceride-rich lipoproteins. Stroke. 1996;27(12): 2166-2172.

86. Austin MA, King KM, Vrannizanm KM, Krauss RM. Atherogenic lipoprotein phenotype. A proposed genetic marker for coronary heart disease risk. Circulation. 1990;82(2):495-506.

87. Ryu JE, Howard G, Craven TE, Bond MG, Hagaman AP, Crouse JR. Postprandial triglyceridemia and carotid atherosclerosis in middleaged subjects. Stroke. 1992;23(6):823-828.

88. Sharrett AR, Chambless LE, Heiss G, Paton CC, Patsch W. Association of postprandial triglyceride and retinyl palmitate responses with asymptomatic carotid artery atherosclerosis in middle-aged men and women. The Atherosclerosis Risk in Communities (ARIC) Study. Arterioscler Thromb Vasc Biol. 1995;15(12):2122-2129.

89. Meyer E, Westerveld HE, De Ruijter-Heijstek FC, et al. Abnormal postprandial apolipoprotein B-48 and triglyceride responses in normolipidemic women with greater than $70 \%$ stenotic coronary artery disease: A case-control study. Atherosclerosis. 1996;124(2):221-235.

90. Karpe F, de Faire U, Mercuri M, Bond MG, et al. Magnitude of alimentary lipemia is related to intima-media thickness of the common carotid artery in middle-aged men. Atherosclerosis. 1998;141(2): 307-314.

91. Cromwell WC, Otvos JD, Keyes MJ, et al. LDL Particle Number and Risk of Future Cardiovascular Disease in the Framingham Offspring Study - Implications for LDL Management. J Clin Lipidol. 2007;1(6): 583-1592.

92. Zaman GS, Rahman S, Rahman J. Postprandial lipemia in pre- and postmenopausal women. J Nat Sci Biol Med. 2012;3(1):65-70.

93. Giannattasio C, Zoppo A, Gentile G, et al. Acute effect of high-fat meal on endothelial function in moderately dyslipidemic subjects. Arterioscler Thromb Vasc Biol. 2005;25(2):406-410.

94. Moyer MP, Tracy RP, Tracy PB, van't Veer C, Sparks CE, Mann KG. Plasma lipo-proteins support prothrombinase and other procoagulant enzymatic complexes. Arterioscler Thromb Vasc Biol. 1998;18(3): 458-465.

95. Kohler HP, Grant PJ. Plasminogen-activator inhibitor type 1 and coronary artery disease. $N$ Engl J Med. 2000;342(24):1792-1801.

96. Murphy AJ, Woollard KJ, Hoang A, et al. High-density lipoprotein reduces the human monocyte inflammatory response. Arterioscler Thromb Vasc Biol. 2008;28(11):2071-2077.

97. Mineo C, Deguchi H, Griffin JH, Shaul PW. Endothelial and antithrombotic actions of HDL. Circ Res. 2006;98(11): 1352-1364.

98. Shao B, Oda MN, Oram JF, Heinecke JW. Myeloperoxidase: an oxidative pathway for generating dysfunctional high-density lipoprotein. Chem Res Toxicol. 2010;23(3):447-454.

99. The TG and HDL Working Group of the Exome Sequencing Project, National Heart, Lung, and Blood Institute. Loss-of-Function Mutations in APOC3, Triglycerides, and Coronary Disease. $N$ Engl J Med. 2014;371(1):22-31.

100. Sievenpiper JL, do Souza RJ, Cozma AI, Chiavarilo L, Ha V, Mirrahimi A. Fructose vs Glucose and metabolism: do the metabolic differences matter? Curr Opin Lipidol. 2014;25(1):8-19.

101. King AC, Haskell WL, Young DR, Oka RK, Stefanick ML. Long-term effects of varying intensities and formats of physical activity on participation rates, fitness and lipoproteins in men and women aged 50 to 65 years. Circulation. 1995;91(10):2596-2604. 
102. Staels B, Dallongeville J, Auwerx J, Schoonjans K, Leitersdorf E, Fruchart JC. Mechanism of action of fibrates on lipid and lipoprotein metabolism. Circulation. 1998;98(19):2088-2093.

103. Fruchart JC, Brewer HB Jr, Leitersdorg E. Consensus of the use of fibrates in the treatment of dyslipidemia and coronary heart disease. Fibrates Consensus Group. Am J Cardiol. 1998;81(7):912-917.

104. Rader DJ, Haffner SM. Role of fibrates in the management of hypertriglyceridemia. Am J Cardiol. 1999;83(9B):30F-35F.

105. Elisaf M. Effects of fibrates on serum metabolic parameters. Curr Med Res and Opin. 2002;18(5):269-276.

106. Jones PH, Pownall HJ, Patsch W, et al. Effect of gemfibrozil on levels of lipoprotein[a] in type II hyperlipoproteinemic subjects. J Lipid Res. 1996;37(6):1298-1308.

107. Dierkes J, Westphal S, Luley C. Fenofibrate-induced hyperhomocystenemia clinical Farnier M. Update on the clinical utility of fenofibrate in mixed dyslipidemias: mechanisms of action and rational prescribing. Vasc Health Risk Manag. 2008;4(5):991-1000.

108. Arad Y, Ramakrishnan R, Ginsberg HN. Lovastatin therapy reduces low density lipoprotein apoB levels in subjects with combined hyperlipidemia by reducing the production of apoB-containing lipoproteins: implications for the pathophysiology of apoB production. J Lipid Res. 1990;31(4):567-582.

109. Conde K, Vergara-jimenez M, Krause BR, Newton RS, Fernandez ML. Hypocholesterolemic actions of atorvastatin are associated with alterations on hepatic cholesterol metabolism and lipoprotein composition in the guinea pig. J Lipid Res. 1996;37(11):2372-2382.

110. Ness GC, Zhao Z, Lopez D. Inhibitors of cholesterol biosynthesis increase hepatic low-density lipoprotein receptor protein degradation. Arch Biochem Biophys. 1996;325(2):242-248.

111. Ness GC, Chambers CM, Lopez D. Atorvastatin action involves diminished recovery of hepatic HMG-CoA reductase activity. J Lipid Res. 1998;39(1):75-84.

112. Jones PH, Davidson MH. Reporting rate of rhabdomyolisis with fenofibrate + statin versus gemfibrozil + any statin. Am J Cardiol. 2005;95(1):120-122.

113. Sattar N, Preiss D, Murray HM, et al. Statins and risk of incident diabetes: a collaborative meta-analysis of randomised statin trials. Lancet. 2010;375(9716):735-742.

114. Preiss D, Seshasai SR, Welsh P, et al. Risk of incident diabetes with intensive-dose compared with moderate-dose statin therapy: a metaanalysis. JAMA. 2011;305(24):2556-2564.

115. Ridker PM, Pradhan A, Macfadyen JG, Libby P, Glynn RJ. Cardiovascular benefits and diabetes risks of statin therapy in primary prevention: an analysis from the JUPITER trial. Lancet. 2012;380(9841):565-571.

116. Carter AA, Gomes T, Camacho X, Jurlink DN, Shah BR, Mamdani MM. Risk of incident diabetes among patients treated with statins: population based study. BMJ. 2013;346:f2610.

117. Dormuth CT, Filion KB, Paterson JM, et al. Higher potency statins and the risk of new diabetes: multicenter observational study of administrative databases. BJM. 2014;48:g3244.

118. Frick MH, Elo O, Haapa K, et al. Helsinki Heart Study: primary-prevention trial with gemfibrozil in middle-aged men with dyslipidemia. Safety of treatment, changes in risk factors, and incidence of coronary heart disease. $N$ Engl J Med. 1987;317(20):1237-1245.

119. Rubins HB, Robins SJ, Collins D, et al. Gemfibrozil for the secondary prevention of coronary heart disease in men with low levels of high-density lipoprotein cholesterol. Veterans Affairs High-Density Lipoprotein Cholesterol Intervention Trial Study Group. $N$ Engl $J$ Med. 1999;341(6):410-418.

120. The Bezafibrate Infarction Prevention (BIP) study. Secondary prevention by raisin HDL cholesterol and reducing triglycerides in patients with coronary artery disease. Circulation. 2000;102(1):21-27.

121. [No authors listed]. Effect of fenofibrate on progression of coronaryartery disease in type 2 diabetes: The Diabetes Atherosclerosis Intervention Study, A randomized Study. Lancet. 2001;357(9260): 905-910.
122. Keech A, Simes RJ, Barter P, et al. Effects of long-term fenofibrate therapy on cardiovascular events in 9795 people with type 2 diabetes mellitus (the FIELD study): randomised controlled trial. Lancet. 2005;366(9500):1849-1861.

123. Ting RD, Keech AC, Drury PL, et al. Benefits and safety of long-term fenofibrate therapy in people with type 2 diabetes and renal impairment: the FIELD Study. Diabetes Care. 2012;35(2): 218-225.

124. Jun M, Foote C, Lv J, et al. Effects of fibrates on cardiovascular outcomes: a systematic review and meta-analysis. Lancet. 2010; 375(9729): 1875-1884.

125. Study of the effectiveness of additional reduction in cholesterol and homocysteine (SEARCH) Collaborative Group, Armitage J, Bowman L. Intensive lowering of LDL cholesterol with $80 \mathrm{mg}$ versus $20 \mathrm{mg}$ simvastatin daily in 12,064 survivors of myocardial infarction: a double-blind randomized trial. Lancet. 2010;376(9753): 1658-1669.

126. Rosen JB, Jimenez JG, Pirags V, et al. Consistency of effect of ezetimibe/simvastatin compared with intensified lipid-lowering treatment strategies in obese and non-obese diabetic subjects. Lipids Health Dis. 2013;12(1):103.

127. Nakajima N, Miyauchi K, Yokoyama T, et al. Effect of combination of ezetimibe and statin on coronary plaque regression in patients with acute coronary syndrome ZEUS trial (eZEtimibe Ultrasound Study). IJC Metabolic and Endocrine. 2014;3:8-13.

128. Tenenbaum A, Fisman EZ. Fibrates are an essential part of modern anti-dyslipidemic arsenal: spotlight on atherogenic dyslipidemia and residual risk reduction. Cardiovascular Diabetology. 2012; 11:125:1-10.

129. Reiner Z. Combined therapy in the treatment of dyslipidemia. Fundamental and Clinical Pharmacology. 2010;24(1):19-28.

130. Reiner Z. Managing the residual cardiovascular disease risk associated with HDL-cholesterol and triglycerides in statin-treated patient: A clinical update. Nutrition, Metabolism and Cardiovascular Disease. 2013;23(9):799-807.

131. Bergman AJ, Murphy G, Burke J, et al. Simvastatin does not have a clinically significant pharmacokinetic interaction with fenofibrate in humans. J Clin Pharmacol. 2004;44(9):1054-1062.

132. Kontopoulos AG, Athyros VG, Papageorgiou AA, Hatzikonstandinou HA, Mayroudi MC, Boudoulas H. Effects of simvastatin and ciprofibrate alone and in combination on lipid profile, plasma fibrinogen and low density lipoprotein particle structure and distribution in patients with familial combined hyperlipidaemia and coronary artery disease. Coron Artery Dis. 1996;7(11):843-850.

133. Shah HD, Parikh KH, Chag MC, et al. Beneficial effects of the addition of fenofibrate to statin therapy in patients with acute coronary syndrome after percutaneous coronary interventions. Exp Clin Cardiol. 2007;12(2):91-96.

134. Ooi T, Heinone T, Alaupovic P, et al. Efficacy and safety of a new hydroximethyglutary-Coenzyme A reductase inhibitor, atorvastatin, in patients with combined hyperlipidemia:comparison with fenofibrate. Arterioscler Thromb Vasc Biol. 1997;17(9):1793-1799.

135. Athyros VG, Papageorgiou AA, Hatzikonstandinou HA, et al. Safety and efficacy of long-term statin-fibrate combinations in patients with refractory familial combined hyperlipidemia. Am J Cardiol. 1997;80(5):608-613.

136. Kirchgässler KU, Schiffner-rohe J, Stahlheber U. Cost effectiveness of micronised fenofibrate and simvastatin in the short-term treatment of type IIa and type IIb hyperlipidaemia. Pharmacoeconomics. 1997; 12(2 Pt 2):237-246.

137. Ellen RL, McPherson R. Long-term efficacy and safety of fenofibrate and a statin in the treatment of combined hyperlipidemia. Am J Cardiol. 1998;81(4A):60B-65B.

138. Murdock DK, Murdock AK, Murdock RW, et al. Long-term safety and efficacy of combination gemfibrozil and HMG-CoA reductase inhibitors for the treatment of mixed lipid disorders. Am Heart $J$. 1999;138(1 Pt 1):151-155. 
139. Weinstein DL, Williams LA, Carslon DM, et al. A Randomized, Double-Blind Study of Fenofibric Acid Plus Rosuvastatin Compared With Rosuvastatin Alone in Stage 3 Chronic Kidney Disease. Clin Ther. 2013;35;(8):1186-1198.

140. Papadakis JA, Ganotakis ES, Jagroop IA, Winder AF, Mikhailidis DP. Statin + fibrate combination therapy fluvastatin with bezafibrate or ciprofibrate in high risk patients with vascular disease. Int $J$ Cardiol. 1999;69(3):237-244.

141. Spieker LE, Noll G, Hannak M, Luscher TF. Efficacy and tolerability of fluvastatin and bezafibrate in patients with hyperlipidemia and persistently high triglyceride levels. J Cardiovasc Pharmacol. 2000;35(3): 361-365.

142. Gavish D, Leibovitz E, Shapira I, Rubinstein A. Bezafibrate and simvastatin combination therapy for diabetic dyslipidaemia: efficacy and safety. J Intern Med. 2000;247(5):563-569.

143. Muhlestein JB, May HT, Jensen JR, et al. The reduction of inflammatory biomarkers by statin, fibrate, and combination therapy among diabetic patients with mixed dyslipidemia: the DIACOR (Diabetes and Combined Lipid Therapy Regimen) study. J Am Coll Cardiol. 2006;48(2):396-401.

144. Shek A, Ferrill MJ. Statin-fibrate combination therapy. Ann Pharmacother. 2001;35(7-8):908-917.

145. Wilmink HW, Twickler MB, Banga JD, et al. Effect of statin versus fibrate on postprandial endothelial dysfunction: role of remnant-like particles. Cardiovasc Res. 2001;50(3):577-582.

146. Kayikciogly M, Ozerkan F, Soydan I. Effectiveness and safety of alternative-day simvastatin and fenofibrate on mixed hyperlipidemia. Am J Cardiol. 1999;83(7):1135-1137.

147. Chan SY, Mancini GBJ, Ignszewski A, Frolich J. Statins but not fibrates improve the atherogenic to anti-atherogenic lipoprotein particle ratio: a randomized crossover study. BMC Clinical Pharmacology. 2008;8:10.

148. Goldberg AC, Bays HE, Ballantyne CM, et al. Efficacy and safety of ABT-335 (fenofibric acid) in combination with atorvastatin in patients with mixed dyslipidemia. Am J Cardiol. 2009;103(4): $515-522$.

149. Ansquer JC, Corda C, Le Malicot K, Jessent V. Effects of atorvastatin $120 \mathrm{mg}$ and fenofibrate $200 \mathrm{mg}$ on the low-density lipoprotein profile in dyslipidemic patients: a 12 week, multicentric, randomized, open-label, parallel group study. Curr Ther Res Clin Exp. 2009;70(2): 71-93.

150. Yang LP, Keating GM. Fenofibric acid: in combination therapy in the treatment of mixed dyslipidemia. Am J Cardiovasc Drugs. 2009;9(6):401-409.

151. Athyros VG, Kakafika AI, Karagiannis A, Mikhaiidis DP. Effects of simvastatin alone versus fenofibrate alone versus simvastatin plus fenofibrate on lipoprotein subparticle profiles in patients with diabetes mellitus and mixed dyslipidemia. Am J Cardiol. 2008;101(11): $1679-1680$

152. Vega GL, Ma PT, Cater NB, et al. Effects of adding fenofibrate $(200 \mathrm{mg} /$ day $)$ to simvastatin $(10 \mathrm{mg} /$ day $)$ in patients with combined hyperlipidemia and metabolic syndrome. Am J Cardiol. 2003;91(8):956-960.

153. Stefanutti C, Bucci A, Di Giacomo S, et al. Efficacy, safety and tolerability of combined-low dose simvastatin-fenofibrate treatment in primary mixed hyperlipidaemia. Clin Drug Investig. 2004;24(8): 465-477.

Research and Reports in Endocrine Disorders

\section{Publish your work in this journal}

Research and Reports in Endocrine Disorders is an international, peerreviewed, open access journal publishing original research, reports, reviews and commentaries on all areas of endocrinology, endocrine disorders and therapeutic interventions. The manuscript management system is completely online and includes a very quick and fair
154. Grundy SM, Vega GL, Yuan Z, Battisti WP, Brady WE, Palmisano J. Effectiveness and tolerability of simvastatin plus fenofibrate for combined hyperlipidemia (the SAFARI trial). Am J Cardiol. 2005;95(4): 462-468.

155. May HT, Anderson JL, Pearson RR, et al. Comparison of the effects of simvastatin alone versus fenofibrate alone versus simvastatin plus fenofibrate on lipid subparticle profiles in diabetic patients with mixed dyslipidemia (from the Diabetes and Combined Lipid Therapy Regimen study). Am J Cardiol. 2008;101(4):486-489.

156. Bays HE, Jones PH, Mohiuddin SM, et al. Long-term safety and efficacy of fenofibric acid in combination with statin therapy for the treatment of patients with mixed dyslipidemia. J Clin Lipidol. 2008;2(6):426-435.

157. Derosa G, Maffioli P, Salvadeo SA. Fenofibrate, simvastatin and their combination in the management of dyslipidaemia in type 2 diabetic patients. Curr Med Res Opin. 2009;25(8):1973-1983.

158. Mohiuddin SM, Pepine CJ, Kelly MT, et al. Efficacy and safety of ABT-335 (fenofibric acid) in combination with simvastatin in patients with mixed dyslipidemia: a phase 3, randomized, controlled study. Am Heart J. 2009;157(1):195-203.

159. Jones PH, Cusi K, Davidson MH, et al. Efficacy and safety of fenofibric acid co-administered with low- or moderate-dose statin in patients with mixed dyslipidemia and type 2 diabetes mellitus: results of a pooled subgroup analysis from three randomized, controlled, double-blind trials. Am J Cardiovasc Drugs. 2010;10(2):73-84.

160. Farnier M, Steinmetz A, Rettersol K, Csaszar A. Fixed-dose combination fenofibrate/pravastatin $160 / 40 \mathrm{mg}$ versus simvastatin $20 \mathrm{mg}$ monotherapy in adults with type 2 diabetes and mixed hyperlipidemia uncontrolled with simvastatin $20 \mathrm{mg}$ : a double-blind, randomized comparative study. Clin Ther. 2011;33(1):1-12.

161. Filippatos TD, Elisaf MS. Fenofibrate plus simvastatin (fixed-dose combination) for the treatment of dyslipidaemia. Expert Opin Pharmacother. 2011;12(12):1945-1958.

162. Tonkin AM, Chen L. Effects of combination lipid therapy in the management of patients with type 2 diabetes mellitus in the Action to Control Cardiovascular Risk in Diabetes (ACCORD) trial. Circulation. 2010;122(8):850-852.

163. Karbasi-Afshar R, Shahmari A, Saburi A. Echocardiographic and exercise test findings in patients with dyslipidemia and coronary artery disease before and after treatment with simvastatin with or without fenofibrate. Int Cardiovas Res J. 2011;5(4):143-147.

164. Davidson MH, Rosenson RS, Maki KC, et al. Effects of fenofibric acid on carotid Intima-media thickness in patients with mixed dyslipidemia on atorvastatin therapy: randomised placebo, controlled study (FIRST) Arterioscler Thromb Vasc Biol. 2014;34(6):1298-1306.

165. Rosenson RS, Wolff DA, Huskin AL, Helenowski IB, Rademaker AW. Fenofibrate therapy ameliorates fasting and postprandial lipoproteinemia, oxidative stress, and the inflammatory response in subjects with hypertriglyceridemia and the metabolic syndrome. Diabetes Care. 2007;30(8):1945-1951.

166. Reyes-Soffer G, Ngai CI, Lovato L, et al. Effect of combination therapy with fenofibrate and simvastatin on postprandial lipemia in the ACCORD lipid trial. Diabetes Care. 2013;36(2):422-428.

167. Koval' O. Simvastatin and Fenofibrate vs Simvastatin Alone in Patients With Type 2 Diabetes Mellitus and Acute Coronary Syndrome. Available from: http://ClinicalTrials.gov/show/NCT02015988. NLM identifier: NCT02015988. Accessed October 5, 2014.

\section{Dovepress}

peer-review system. Visit http://www.dovepress.com/testimonials.php to read real quotes from published authors. 